NASA Technical Memorandum 106016

\title{
Effects of Thermal and Mechanical Fatigue on the Flexural Strength of G40-600/PMR-15 Cross-Ply Laminates
}

Gary D. Roberts

Lewis Research Center

Cleveland, Ohio

and

Barry P.H. Ho and John F. Wallace

Case Western Reserve University

Cleveland, Ohio

February 1993 


\title{
EFFECTS OF THERMAL AND MECHANICAL FATIGUE ON THE FLEXURAL STRENGTH OF G40-600/PMR-15 CROSS-PLY LAMINATES
}

\author{
Gary D. Roberts \\ National Aeronautics and Space Administration \\ Lewis Research Center \\ Cleveland, Ohio 44135 \\ and \\ Barry Ping Hsiao Ho and John F. Wallace \\ Case Western Reserve University \\ Cleveland, Ohio 44106
}

\begin{abstract}
The effects of thermal and mechanical fatigue on the flexural strength of G40-600/ PMR-15 cross-ply laminates with ply orientations of $\left(\mathrm{O}_{2}, 9 \mathrm{O}_{2}\right)_{2 \mathrm{~S}}$ and $\left(9 \mathrm{O}_{2}, \mathrm{O}_{2}\right)_{2 \mathrm{~S}}$ are examined. The relative importance of shear and tensile stresses is examined by varying the span-to-depth ratios of flexural test specimens from 8 to 45 . Acoustic emission signals are measured during the flexural tests in order to monitor the initiation and growth of damage. Optical microscopy is used to examine specimens for resin cracking, delamination, and fiber breaks after testing. Transverse matrix cracks and delaminations occur in all specimens, regardless of ply orientation, span-to-depth ratio, or previous exposure of specimens to thermal and mechanical fatigue. A small amount of fiber tensile fracture occurs in the outer $0^{\circ}$ ply of specimens with high span-todepth ratios. Because of the complex failure modes, the flexural test results represent the “apparent" strengths rather than the true flexural or shear strengths for these cross-ply laminates. Thermal cycling of specimens prior to flexural testing does not reduce the apparent flexural strength or change the mode of failure. However, fewer acoustic events are recorded at all strains during flexural testing of specimens exposed to prior thermal cycling. High temperature thermal cycling ( 32 to $260^{\circ} \mathrm{C}, 100$ cycles) causes a greater reduction in acoustic events than low temperature thermal cycling ( -85 to $85^{\circ} \mathrm{C}, 500$ cycles). Mechanical cycling
\end{abstract}


( 0 to 50 percent of the flexural strength, 100 cycles) has a similar effect, except that acoustic events are reduced only at strains less than the maximum strain applied during flexural fatigue.

\section{INTRODUCTION}

High performance, polymer matrix composites (PMC's) are used in aeronautic and space applications because of their high stiffness and high strength-to-weight ratio. Since PMC's used in these applications are exposed to a wide range of temperatures, their service life is often limited by the damage formed during thermal cycling. In space applications, temperatures vary as an orbiting satellite moves in and out of Earth's shadow. In aircraft engine applications, rapid heating occurs during takeoff, and temperatures vary from ambient to about $300{ }^{\circ} \mathrm{C}$ during flight. Microcracking induced by thermal cycling and oxidative degradation can be tolerated in engine applications as long as critical mechanical properties, such as compressive strength, are not degraded below acceptable limits. Although the performance advantages of PMC's have been demonstrated in military aircraft engines, use of PMC's in commercial aircraft engines is only recently being considered. Before PMC's can be used for load bearing structures in commercial engines, a better understanding of damage initiation and growth during thermal cycling is needed so that reliable models can be developed for predicting their service life. This information is also needed so that reliable test methods can be developed for evaluating new resins with improved resistance to damage induced by thermal cycling. Flexural tests are often used to evaluate new high temperature matrix resins and to study the degradation of composite properties after thermal cycling and high temperature isothermal aging. Although the failure mode for PMC's in flexure is often complex, flexural tests are one of the few techniques which can be used to provide information about composite properties when limited amounts of material are available. The reliability and usefulness of flexural test data are improved if failure mechanisms are monitored during testing. Analysis of the acoustic signals emitted during mechanical deformation can provide information about the onset of damage and, in some cases, 
the type of failure (i.e., fiber tensile fracture, matrix cracking, fiber/matrix debonding). Acoustic emission data has provided useful information about the failure process for graphite/epoxy PMC's tested in tension, flexure, and fatigue,${ }^{1-5}$ but little information is available for high temperature polyimide matrix materials such as PMR-15. In this work, acoustic emission was recorded during three- and four-point flexure testing of graphite/PMR-15 cross-ply laminates. The effects of low temperature thermal cycling, high temperature thermal cycling, and mechanical cycling on the flexural strength and modes of failure were examined.

\section{EXPERIMENTAL PROCEDURES}

Fabrication of Laminates and Test Specimens

The G40-600/PMR-15 prepreg used in this work was supplied by Ferro Corporation. The 16 plies of prepreg required for a $\left(\mathrm{O}_{2}, 9 \mathrm{O}_{2}\right)_{2 \mathrm{~S}}$ layup were cut and stacked in a 15.2 - by 30.5 -cm (6- by 12-in.) tray with fibers in the outer plies aligned along the $30.5-\mathrm{cm}$ (12-in.) length. A metal plate was placed on top of the stack to provide slight pressure. The tray was then placed in an oven at $204{ }^{\circ} \mathrm{C}$ for $1 \mathrm{hr}$ to imidize the PMR-15 monomers. The imidized material was then placed in a tight fitting 15.2 - by 30.5 -cm (6- by 12 -in.) mold and cured in a press under 500 psi pressure for $2 \mathrm{hr}$ at $316^{\circ} \mathrm{C}$. The laminate was removed from the mold and postcured in an oven for $16 \mathrm{hr}$ at $316^{\circ} \mathrm{C}$. The volume fraction of fibers measured by digestion of the matrix with sulfuric acid was 0.70 . Laminates were C-scanned to verify that there were no delaminations present. Test specimens in the shape of rectangular beams were cut from the laminates using a water-cooled, diamond-impregnated cutting wheel. Beams cut parallel to the length of the laminate had fibers in the outer plies parallel to the beam length, or a $\left(\mathrm{O}_{2}, 9 \mathrm{O}_{2}\right)_{2 \mathrm{~S}}$ layup. Beams cut perpendicular to the length of the laminate had fibers in the outer plies perpendicular to the beam length, or a $\left(9 \mathrm{O}_{2}, \mathrm{O}_{2}\right)_{2 \mathrm{~S}}$ layup. Edges of the beams were examined for transverse cracking using an optical microscope. No cracks were visible on the cut edges of the beams prior to testing. 


\section{Flexural Tests}

Three- and four-point flexure tests were conducted according to the test procedure described in ASTM D $790^{6}$ using an Instron Model 1123 test machine. The three-point flexure specimens were $5.8 \mathrm{~mm}$ wide and $2.2 \mathrm{~mm}$ thick. Span lengths were set to provide span-to-depth ratios ranging from 8 to 45 . Three specimens were tested at each span-to-depth ratio. Error bars are calculated as plus or minus two standard deviations. The rate of cross-head displacement ranged from 0.25 to $5 \mathrm{~mm} / \mathrm{min}$ in order to obtain an effective strain rate close to $0.01 \mathrm{~min}^{-1}$ for the various span-to-depth ratios, as described in ASTM D 790. Four-point flexure specimens were $5.8 \mathrm{~mm}$ wide, $2.2 \mathrm{~mm}$ thick, and $120 \mathrm{~mm}$ long. A span-to-depth ratio of 45 and a deflection rate of $5 \mathrm{~mm} / \mathrm{min}$ were used for all four-point bend tests. The load span was one half the support span.

According to the ASTM D 790 test procedure, the maximum strain at failure in the outer ply of the laminate can be calculated for three- and four-point bend tests using Eqs. (1) and (2),

$$
\begin{gathered}
r=6 \mathrm{Dd} / \mathrm{L}^{2} \quad(\text { three-point bend }) \\
\mathrm{r}=4.36 \mathrm{Dd} / \mathrm{L}^{2} \quad \text { (four-point bend) }
\end{gathered}
$$

and the apparent flexural strength can be calculated using Eqs. (3) and (4).

$$
\begin{array}{cl}
\mathrm{S}=3 \mathrm{PL} / 2 \mathrm{bd}^{2} & \text { (three-point bend) } \\
\left.\mathrm{S}=3 \mathrm{Pl} / 4 \mathrm{bd}^{2} \quad \text { (four-point bend }\right)
\end{array}
$$

where

D midspan deflection

L support span

d depth of beam

b width of beam

P applied load 
A procedure for measuring the apparent interlaminar shear strength of composite beams with low span-to-depth ratios is described in ASTM D 2344. ${ }^{7}$ According to this test procedure, the apparent interlaminar shear strength of three-point bend specimens can be calculated using Eq. (5).

$$
\mathrm{S}=0.75 \mathrm{P} / \mathrm{bd}
$$

Several limitations exist on the use of Eqs. (1) to (5) for the cross-ply laminates investigated in this work. The applicability of these equations is discussed below along with the test results.

Thermal and Mechanical Cycling

Flexural test specimens were exposed to low temperature thermal cycling, high temperature thermal cycling, mechanical cycling, and combined low temperature thermal cycling followed by mechanical cycling. For low temperature cycling, specimens were placed in a cylindrical sample holder and locked into an air actuated piston. The specimens were then cycled 500 times between a chamber heated to $85^{\circ} \mathrm{C}$ and a chamber cooled to $-85^{\circ} \mathrm{C}$. The heating rate was estimated to be about $60^{\circ} \mathrm{C} / \mathrm{min}$, and the cooling rate was estimated to be about $100{ }^{\circ} \mathrm{C} / \mathrm{min}$. High temperature thermal cycling was conducted using a MOEN HT251 thermal cycler made by Heat Transfer Technologies, Inc. The specimens were suspended in racks which were placed inside the thermal cycling unit. The temperature was then cycled between 32 and $260^{\circ} \mathrm{C}$ for 100 cycles. The heating ramp was linear with a heating rate of $26.7^{\circ} \mathrm{C} / \mathrm{min}$ $\left(80^{\circ} \mathrm{F} / \mathrm{min}\right)$. The maximum cooling rate was $32.8^{\circ} \mathrm{C} / \mathrm{min}\left(91^{\circ} \mathrm{F} / \mathrm{min}\right)$ at the beginning of the cooling cycle, but the cooling rate decreased steadily throughout the cycle. Mechanical cycling was conducted using four-point bend specimens deformed to 50 percent of the fracture load for 100 cycles at a deflection rate of $5 \mathrm{~mm} / \mathrm{min}$.

\section{Acoustic Emission Detection}

A NANO 30 acoustic sensor was attached to the specimens to monitor acoustic events during the flexural tests. High vacuum silicone grease was used as a coupling medium. The 
acoustic sensor was connected to a $40 \mathrm{~dB}$ gain pre-amplifier with a resonant frequency of $300 \mathrm{kHz}$. A cable delivered the data from the pre-amplifier to a SPARTAN AT data analyzer made by Physical Acoustics Corporation with a threshold gain of $26 \mathrm{~dB}$. These test parameters have been shown by previous studies to provide the best behavior information.

\section{RESULTS AND DISCUSSION}

\section{Three-Point Bend Test Results}

Typical load-deflection curves for the $\left(\mathrm{O}_{2}, 9 \mathrm{O}_{2}\right)_{2 \mathrm{~S}}$ specimens are shown in Fig. 1. The acoustic events recorded during deformation are shown in Fig. 2. Similar data are shown in Figs. 3 and 4 for the $\left(9 \mathrm{O}_{2}, \mathrm{O}_{2}\right)_{2 \mathrm{~S}}$ specimens. Note that different deflection rates were used for different span-to-depth ratios (as specified in ASTM D 790), so the failure times indicated in Figs. 2 and 4 must be multiplied by the appropriate deflection rate to give the deflections at failure shown in Figs. 1 and 3 . The flexural strain (i.e., the maximum tensile strain in the outer ply) can be calculated using Eq. (1). At low strains, the load-deflection curves are linear, and few acoustic events are recorded. At higher strains, the slopes of the load-deflection curves decrease, and the acoustic events increase until failure. Acoustic events begin at lower strains for specimens with higher span-to-depth ratios. In Fig. 2, for example, acoustic events begin to increase at a strain of 0.22 percent $(t=20 \mathrm{sec})$ when the span-to-depth ratio is 45 and at a strain of 0.62 percent $(t$ $=35 \mathrm{sec}$ ) when the span-to-depth ratio is 8 .

Since the maximum strain at failure is less than 1.5 percent for all span-to-depth ratios, beam strengths are calculated according to Eq. (3), which includes no correction for large deflections. Strengths calculated according to Eq. (3) represent true flexural strengths only at high span-to-depth ratios and only when failure occurs in the outer fibers. In addition, Eq. (3) is strictly valid only for homogeneous, elastic beams with linear load-deflection curves. Since these conditions are not satisfied for the graphite/PMR-15 cross-ply laminates used in this work, flexural strengths calculated according to Eq. (3) are called "apparent" strengths, in accordance 
with the terminology in the ASTM D 790 test procedure. Apparent flexural strengths are shown as a function of span-to-depth ratio in Fig. 5. Ideally, tensile failure should occur in the outer ply at high span-to-depth ratios and interlaminar separation should occur near the center plane at low span-to-depth ratios. However, the actual failure modes were more complex. Vertical cracks were present in all $90^{\circ}$ plies, regardless of layup or span-to-depth ratio. These transverse cracks were not concentrated in the vicinity of the load point. Other features of the failure process depended on the span-to-depth ratio. These are described below.

The various types of failure observed on the beam edges after three-point bend testing are shown in Figs. 6(a) to (d). The darker plies are the $90^{\circ}$ plies. The 16 plies are numbered in Fig. 6(a) to help locate features in the micrographs. At span-to-depth ratios of 16 and less, a single delamination occurred near the center of the beam, but the fracture surface was not confined to a single $0^{\circ} / 90^{\circ}$ interface. Instead, the delamination sometimes crossed from one interface to another through the $90^{\circ}$ plies. This usually occurred at the site of a vertical crack or at a $45^{\circ}$ crack located near a vertical crack. For $\left(9 \mathrm{O}_{2}, \mathrm{O}_{2}\right)_{2 \mathrm{~S}}$ specimens, delamination alternated between the $4 / 5$ interface and the 6/7 interface. This type of failure is shown in Fig. $6(a)$ for a $\left(9 \mathrm{O}_{2}, \mathrm{O}_{2}\right)_{2 \mathrm{~S}}$ specimen with a span-to-depth ratio of 8 . The delamination starts on the left at the $4 / 5$ interface, crosses through plies 5 and 6 at a $45^{\circ}$ angle, then continues to the right along the $7 / 8$ interface. For $\left(\mathrm{O}_{2}, 9 \mathrm{O}_{2}\right)_{2 \mathrm{~S}}$ specimens, four $90^{\circ}$ plies are at the center of the beam. Delamination alternated between the $6 / 7$ and the $10 / 11$ interfaces on either side of the central $90^{\circ}$ plies.

At span-to-depth ratios of 25 and greater, transverse cracks and multiple delaminations occurred for both $\left(\mathrm{O}_{2}, 9 \mathrm{O}_{2}\right)_{2 \mathrm{~S}}$ and $\left(9 \mathrm{O}_{2}, \mathrm{O}_{2}\right)_{2 \mathrm{~S}}$ specimens (Fig. 6(b)). For $\left(\mathrm{O}_{2}, 9 \mathrm{O}_{2}\right)_{2 \mathrm{~S}}$ specimens, some broken fibers were visible at the edge of the bottom ply (ply 1) but not across the entire bottom surface (Fig. 6(c)). The number of broken fibers increased as span-to-depth ratio increased from 25 to 45 . For $\left(9 \mathrm{O}_{2}, \mathrm{O}_{2}\right)_{2 \mathrm{~S}}$ specimens, some fiber breaks were visible in the 
outermost $0^{\circ}$ ply (ply 3 ) at locations where transverse cracks penetrated the outer $90^{\circ}$ plies (plies 1 and 2). For both $\left(\mathrm{O}_{2}, 9 \mathrm{O}_{2}\right)_{2 \mathrm{~S}}$ and $\left(9 \mathrm{O}_{2}, \mathrm{O}_{2}\right)_{2 \mathrm{~S}}$ specimens, fiber buckling occurred on the upper beam surface (Fig. 6(d)).

The acoustic events recorded during deformation clearly indicate that damage begins to accumulate long before failure. However, it was not possible to determine directly from the acoustic data what type of damage had occurred because the amplitude distribution of the events was broad with no clearly defined peaks corresponding to the various possible failure events. It is also not clear whether the damage observed by post failure analysis occurred before or after initiation of catastrophic failure. Some information can be inferred from the magnitude of the strain in the outer ply at failure. For the $\left(\mathrm{O}_{2}, 9 \mathrm{O}_{2}\right)_{2 \mathrm{~S}}$ specimens with a span-to-depth ratio of 45, the failure strain calculated using Eq. (1) is 1.4 percent. This is close to the fiber failure strain of 1.44 percent measured by the prepreg manufacturer for fibers used in this particular lot of prepreg. As the span-to-depth ratio of the $\left(\mathrm{O}_{2} 9 \mathrm{O}_{2}\right)_{2 \mathrm{~S}}$ specimens decreases from 45 to 25 , the calculated strain at failure decreases only slightly from 1.4 percent. This suggests that flexural strength is determined by fiber tensile strength for $\left(\mathrm{O}_{2}, 9 \mathrm{O}_{2}\right)_{2 \mathrm{~S}}$ specimens with high span-todepth ratios and that damage which accumulates prior to failure has little effect on the apparent flexural strength. For all other specimens, failure is a complex process involving matrix cracking, transverse ply cracking, delamination, and possibly fiber breakage.

The strength of specimens with low span-to-depth ratios is often reported as the interlaminar shear strength (or the short beam shear strength) rather than the flexural strength. A procedure for calculating the "apparent" interlaminar shear strength of parallel fiber reinforced laminates by applying classical beam theory to short-beam shear specimens is described in ASTM D 2344. ${ }^{7}$ This test method is limited to parallel fiber reinforced specimens with span-to-depth ratios of 4 or 5 , and a warning is included in the test procedure that results are meant to be used only for comparative studies and not for generating design data. 
Interlaminar shear test data measured on graphite/epoxy specimens with various ply configurations and span-to-depth ratios as high as 16 has been reviewed by Whitney et al. ${ }^{8,9}$ They concluded that combined compression and shear stresses lead to complex failure modes which limit the usefulness of the test, even for comparative studies. The primary problem is that vertical cracks are formed prior to failure and that the vertical cracks appear to be required to induce delamination. In spite of the limitations of the test method for accurately measuring interlaminar shear strength, the short beam shear test can be useful for assessing the initial quality of a laminate and the degradative effects of environmental exposure. For example, the short beam shear strength will be low if fiber/matrix bonding is poor or if matrix and interface properties have been degraded by exposure of the laminate to high temperatures or thermal cycling. Apparent interlaminar shear strengths of the graphite/PMR-15 specimens are shown in Fig. 7. Note that Figs. 5 and 7 represent the same test data calculated in two different ways (i.e., using Eq. (3) for flexural strength and Eq. (5) for shear strength). If shear strengths calculated according to Eq. (5) were valid, the shear strengths in Fig. 7 should approach a constant value at low span-to-depth ratios. This is not the case for either the $\left(\mathrm{O}_{2}, 9 \mathrm{O}_{2}\right)_{2 \mathrm{~S}}$ or the $\left(9 \mathrm{O}_{2}, \mathrm{O}_{2}\right)_{2 \mathrm{~S}}$ specimens. Although accurate interlaminar shear strengths can not be determined from the data of Fig. 7, it does appear that the $\left(9 \mathrm{O}_{2}, \mathrm{O}_{2}\right)_{2 \mathrm{~S}}$ specimens are stronger than the $\left(\mathrm{O}_{2}, 9 \mathrm{O}_{2}\right)_{2 \mathrm{~S}}$ specimens at low span-to-depth ratios. Since the $\left(\mathrm{O}_{2}, 9 \mathrm{O}_{2}\right)_{2 \mathrm{~S}}$ and $\left(9 \mathrm{O}_{2}, \mathrm{O}_{2}\right)_{2 \mathrm{~S}}$ specimens were cut from the same laminate, the difference in strength must be a result of the ply stacking sequence and the location of failure rather than a difference in the actual interlaminar shear strength between the $0^{\circ}$ and $90^{\circ}$ plies.

Since measurements at low span-to-depth ratios do not appear to represent the true interlaminar shear strength, the effects of thermal cycling on the three-point bend data will be presented only in the form of apparent flexural strength. Low temperature cycling ( -85 to $85^{\circ} \mathrm{C}$ for 500 cycles) was used to simulate thermal loads experienced by satellites in low Earth 
orbit. High temperature cycling ( 32 to $260^{\circ} \mathrm{C}$ for 100 cycles) was used to simulate service conditions for polymer matrix composites in aircraft gas turbine engines. The effect of thermal cycling on the strengths of $\left(0_{2}, 9 \mathrm{O}_{2}\right)_{2 \mathrm{~S}}$ and $\left(9 \mathrm{O}_{2}, \mathrm{O}_{2}\right)_{2 \mathrm{~S}}$ specimens is shown in Figs. 8 and 9 . The failure modes for the uncycled specimens were described above. Thermal cycling had little effect on either the failure modes or the apparent flexural strength. The total number of acoustic events accumulated during deformation was smaller for specimens which had been thermally cycled, with high temperature cycling resulting in a larger reduction in total events. The number of events is lower for the thermally cycled materials because some of the damage which would have been induced during the test by mechanical loading has already occurred during thermal cycling. The maximum density of transverse edge cracks after failure was nearly the same (approximately 2 cracks $/ \mathrm{mm}$ ) for all test pieces, regardless of thermal history. For $\left(\mathrm{O}_{2}, 9 \mathrm{O}_{2}\right)_{2 \mathrm{~S}}$ laminates, the maximum crack density occurred in the $90^{\circ}$ plies adjacent to the outer $0^{\circ}$ plies (plies 3 and 4). For the $\left(9 \mathrm{O}_{2}, \mathrm{O}_{2}\right)_{2 \mathrm{~S}}$ laminates, the maximum crack density occurred in the $90^{\circ}$ plies adjacent to the center $0^{\circ}$ plies (plies 5, 6, 11, and 12).

Two additional sets of three-point bend experiments were conducted in order to examine the growth of damage prior to failure. First, acoustic events were monitored for specimens held under high static loads in order to determine whether stress relaxation and time dependent failure in the matrix were significant. $\mathrm{A}\left(\mathrm{O}_{2}, 9 \mathrm{O}_{2}\right)_{2 \mathrm{~S}}$ specimen with a span-to-depth ratio of $\mathbf{4 5}$ was deformed to 70 percent of the expected failure load. The specimen was then held at constant deflection for $35 \mathrm{~min}$ before the deflection was continued. During the hold at constant deflection, the load remained constant, and only a few acoustic events occurred. The deflection was then continued until the specimen failed. The load at failure was not affected by application of the static load. Similar results were obtained for lower static loads and for $\left(9 \mathrm{O}_{2}, \mathrm{O}_{2}\right)_{2 \mathrm{~S}}$ specimens. This indicates that time dependent effects are not significant for the room temperature tests. In a second set of experiments, $\left(\mathrm{O}_{2}, 9 \mathrm{O}_{2}\right)_{2 \mathrm{~S}}$ specimens with a span-to-depth ratio of 45 were loaded 
and unloaded in a single cycle with maximum loads of $10,30,50,70$, and 90 percent of the expected failure load. After the loading cycle, the specimens were cut in half by making a vertical cut along the length of the specimens. The pieces were then examined for cracks on both the original outer edge of the specimen and on the interior edge of the specimen which was exposed by cutting. Only a few cracks were observed on the outer edges, even after loading to 90 percent of the breaking load. However, cracks were observed on the interior edge with the maximum crack density located near the load point. The maximum crack density in the interior was much lower than the maximum edge crack density reported above $(2$ cracks $/ \mathrm{mm})$ for specimens loaded to failure. The density of interior cracks was not strongly affected by the magnitude of the applied load. This appears to be in conflict with the data of Fig. 2, in which the number of acoustic events increases steadily as the load is increased. However, it is probable that some of the failure events are too small to be visible by optical microscopy at low magnifications. Examination of selected specimens at magnifications up to 500 times did reveal smaller cracks which did not cross an entire ply. Tomkins and Williams ${ }^{10}$ have noted that the extent of microcracking in Celion 6000/PMR-15 laminates could be determined better by x-ray than by optical microscopy. Further work, including x-radiography, is needed to determine the type and location of damage which occurs at various strains during flexure testing of the G40-600/PMR-15 laminates. Since a single acoustic detector was used to obtain the data of Figs. 2 and 4, it was not possible to determine the location of the acoustic events recorded at various times during the load-deflection cycle. Further experiments using two detectors would be useful for determining whether damage induced at low strains is concentrated near the load point.

\section{Four-Point Bend Tests}

As mentioned above, the ideal failure mode for flexural specimens with high span-to-depth ratios is fiber tensile failure in the outer ply at the location of maximum tensile stress. For three- 
point bend specimens, the region of maximum tensile stress is located directly under the load point. However, significant shear stresses are also present in this region. For four-point bend specimens, the region of maximum tensile stress is located between the load points where the specimen is deformed in a pure bending mode. Since the shear stress is zero in pure bending, failure analysis is simplified for four-point bend tests if failure occurs between the load points. Outside of this region (i.e., in the region between the load points and the support points) the shear stress is nonzero. For specimens with the same span-to-depth ratio, the load required to produce a particular value of the maximum tensile stress in a four-point bend test is twice that required in a three-point bend test (Eqs. (3) and (4)). At equal values of the maximum tensile stress, the maximum shear stress in the four-point bend test is twice that in the three-point bend test. ${ }^{11}$ Although this analysis is based on simple beam theory, the shear stress for composite specimens will still be higher in the four-point bend test than in the three-point bend test as long as the specimens have the same ply layup. As a result, specimens which fail in flexure during a three-point bend test may fail in shear during a four-point bend test.

Four-point bend tests were done using $\left(\mathrm{O}_{2}, 9 \mathrm{O}_{2}\right)_{2 \mathrm{~S}}$ and $\left(9 \mathrm{O}_{2}, \mathrm{O}_{2}\right)_{2 \mathrm{~S}}$ specimens with a spanto-depth ratio of 45 . The effects of low temperature thermal cycling $\left(-85\right.$ to $\left.85^{\circ} \mathrm{C}\right)$ for 500 cycles), mechanical cycling (50 percent of fracture load for 100 cycles), and combined cycling (500 low temperature thermal cycles followed by 100 mechanical cycles) were examined. For $\left(\mathrm{O}_{2}, 9 \mathrm{O}_{2}\right)_{2 \mathrm{~S}}$ specimens, extensive transverse cracking was present in all $90^{\circ}$ plies after the flexure tests. Multiple delaminations occurred primarily at $0^{\circ} / 90^{\circ}$ interfaces in the middle and top portions of the beams. Compressive failures were located on the top surface for only two of the specimens. One of these was near a load point, and the other between the load points. For $\left(9 \mathrm{O}_{2}, \mathrm{O}_{2}\right)_{2 \mathrm{~S}}$ specimens, transverse cracks also occurred in all $90^{\circ}$ plies. Total delaminations were located between the top $0^{\circ}$ ply and the $90^{\circ}$ ply below it. Some localized delamination also occurred between other plies. No broken fibers were observed for either $\left(\mathrm{O}_{2}, 9 \mathrm{O}_{2}\right)_{2 \mathrm{~S}}$ or $\left(9 \mathrm{O}_{2}, \mathrm{O}_{2}\right)_{2 \mathrm{~S}}$ 
specimens. Apparent flexural strengths are shown in Table 1. The flexural strengths in Table 1 are lower than those shown in Fig. 5 for the three-point bend specimens with a span-to-depth ratio of 45. The severe delamination, the lack of broken fibers, and the lower apparent flexural strengths for the four-point bend specimens indicate that shear induced delamination occurred before the tensile stress became large enough to break the fibers in the outer ply.

The data of Table 1 indicate that thermal, mechanical, and combined cycling have little effect on the apparent flexural strengths. Acoustic events recorded during testing are shown in Figs. 10 and 11. Although strength is not reduced by thermal and mechanical cycling individually or combined, the number of acoustic events recorded during subsequent testing is reduced. Thermal cycling reduces the number of events recorded at all strains. Mechanical cycling eliminates acoustic events at low strains, but has little effect at higher strains. These results are reasonable since thermal cycling causes damage throughout the specimen, while mechanical cycling causes damage only in regions where damage would normally occur during the first half of the flexural test. The acoustic events recorded during mechanical cycling are shown in Fig. 12 for specimens with no prior thermal cycling and in Fig. 13 for specimens with prior thermal cycling. Most of the damage occurs during the first mechanical cycle. Acoustic events which occur after the first cycle could be caused by further damage or by friction between the surfaces formed by previous damage. Friction has been found to be a major source of acoustic emission during tension fatigue testing of cross-ply laminates. ${ }^{1}$ If the acoustic events recorded during flexural loading were associated with friction, the number of events should increase as the extent of damage is increased by thermal or mechanical cycling. However, the data in Figs. 12 and 13 indicate that both thermal and mechanical cycling reduce the number of events. The acoustic events recorded during mechanical cycling are therefore caused by further damage rather than by friction. The absence of friction related events is consistent with the observation of transverse cracking as the dominant subcritical damage mode since the cracks will 
open and close during mechanical cycling with no sliding (or friction) between the fracture surfaces.

\section{CONCLUSIONS}

A large amount of subcritical damage occurs during flexural loading of G40-600/PMR-15 cross-ply specimens. Apparent flexural strengths of G40-600/PMR-15 cross-ply specimens are not reduced by mechanical and thermal cycling if the damage induced does not exceed that which occurs normally during the flexural test. As a result, flexural strength measurements alone provide little information about the damage induced by thermal and mechanical fatigue. The onset of damage during flexural testing can be easily detected by monitoring acoustic emission with a single detector. Two detectors can be used to determine the location of subcritical damage which occurs at various strains during the flexural test. Further work is needed to determine the types of failure associated with particular acoustic events. More extensive testing of mechanical properties would be required to determine whether or not the damage caused by thermal and mechanical fatigue could be tolerated in a particular application. However, the flexural test data indicate that a substantial amount of damage may be tolerated in applications for which flexural strength is the primary design consideration. This could include some applications for satellites in low Earth orbit, but only if the adverse effects of damage on compressive strength, modulus, and coefficient of thermal expansion could be tolerated. For high temperature aeronautics applications, the reduced compressive strength and the accelerated rate of oxidative degradation caused by microcracking are critical issues. For these applications, acoustic emission measurements provide useful information about the growth of damage during thermal cycling. The feasibility of measuring acoustic emission at higher temperatures and during thermal cycling should therefore be considered. 


\section{REFERENCES}

1. J. Awerbuch, W.F. Eckles, and D.L. Erdman, "Detection of Failure in Cross-Ply Graphite/Epoxy During Fatigue Loading Through Acoustic Emission,” Air Force Report WRDC-TR-89-3087-Vol. 1 (1989).

2. K. Ono, in Proceedings of the 2nd International Symposium on Acoustic Emission from Reinforced Plastics, CARP/Society of Plastics Industry, New York, 1986, pp. 22-28. (Also, in J. Reinfor. Plastic, 7, 90 (1988)).

3. H. Otsuka, J. Composite Materials, 5, 591 (1981).

4. N. Sato, T. Kurauchi, and O. Kamigaito, J. Mater. Sci., 21, 1005 (1986).

5. D.G. Zimcik, D. Prouix, C. Roy, and A. Maslouhi, in The Nation's Future Materials Needs, 19th International SAMPE Technical Conference, SAMPE, Covina, CA, 1987, pp. 360-371.

6. "Test Methods for Flexural Properties of Unreinforced and Reinforced Plastics and Electrical Insulating Materials," ASTM Standard D 790-91.

7. "Test Method for Apparent Interlaminar Shear Strength of Parallel Fiber Composites by Short Beam Method, ASTM D 2344-84 (1989).

8. J.M. Whitney, C.E. Browning, and A. Mair, in Composite Materials: Testing and Design (Third Conference), ASTM STP-546, ASTM, Philadelphia, PA, 1974, pp. 30-45.

9. J.M. Whitney, in Interlaminar Response of Composite Materials, N.J. Pagano, ed., Elsevier, New York, 1989, pp. 161-250.

10. S.S. Tompkins and S.L. Williams, in AIAA/ASME/ASCI/AMS 23rd Structural Dynamics and Materials Conference, AIAA, New York, 1982, pp. 239-246.

11. S.W. Tsai, Composites Design, 4th ed., Think Composites, Dayton, OH, 1988. 
TABLE 1.-EFFECTS OF THERMAL AND MECHANICAL CYCLING ON THE APPARENT FLEXURAL STRENGTH OF

FOUR-POINT BEND SPECIMENS WITH A

SPAN-TO-DEPTH RATIO OF 45

\begin{tabular}{|l|c|c|}
\hline \multirow{2}{*}{ Specimen } & \multicolumn{2}{|c|}{ Apparent flrxural strength, GPa } \\
\cline { 2 - 3 } & $\left(\mathrm{O}_{2}, 9 \mathrm{O}_{2}\right)_{2 \mathrm{~S}}$ & $\left(9 \mathrm{O}_{2}, \mathrm{O}_{2}\right)_{2 \mathrm{~S}}$ \\
\hline No cycling & 1.0 & 0.69 \\
Thermal cycling & 1.1 & .69 \\
Mechanical cycling & 1.0 & .69 \\
Thermal and mechanical cycling & 1.0 & .71 \\
\hline
\end{tabular}

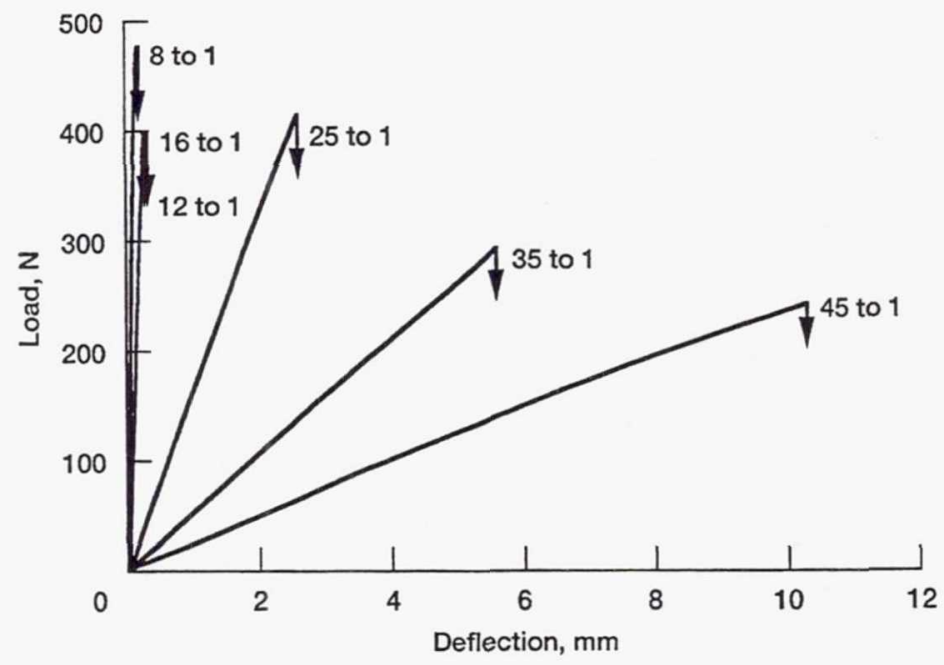

Figure 1.-Load-deflection curves for $\left(\mathrm{O}_{2}, 90_{2}\right)_{2 \mathrm{~S}}$ specimens tested in 3-point bending. Deflection rates (in $\mathrm{mm} / \mathrm{min}$ ) used for the various span/depth ratios are: 5 for $45 / 1,4$ for $35 / 1,2$ for $25 / 1,1$ for $16 / 1,0.5$ for $12 / 1$, and 0.25 for $8 / 1$. 

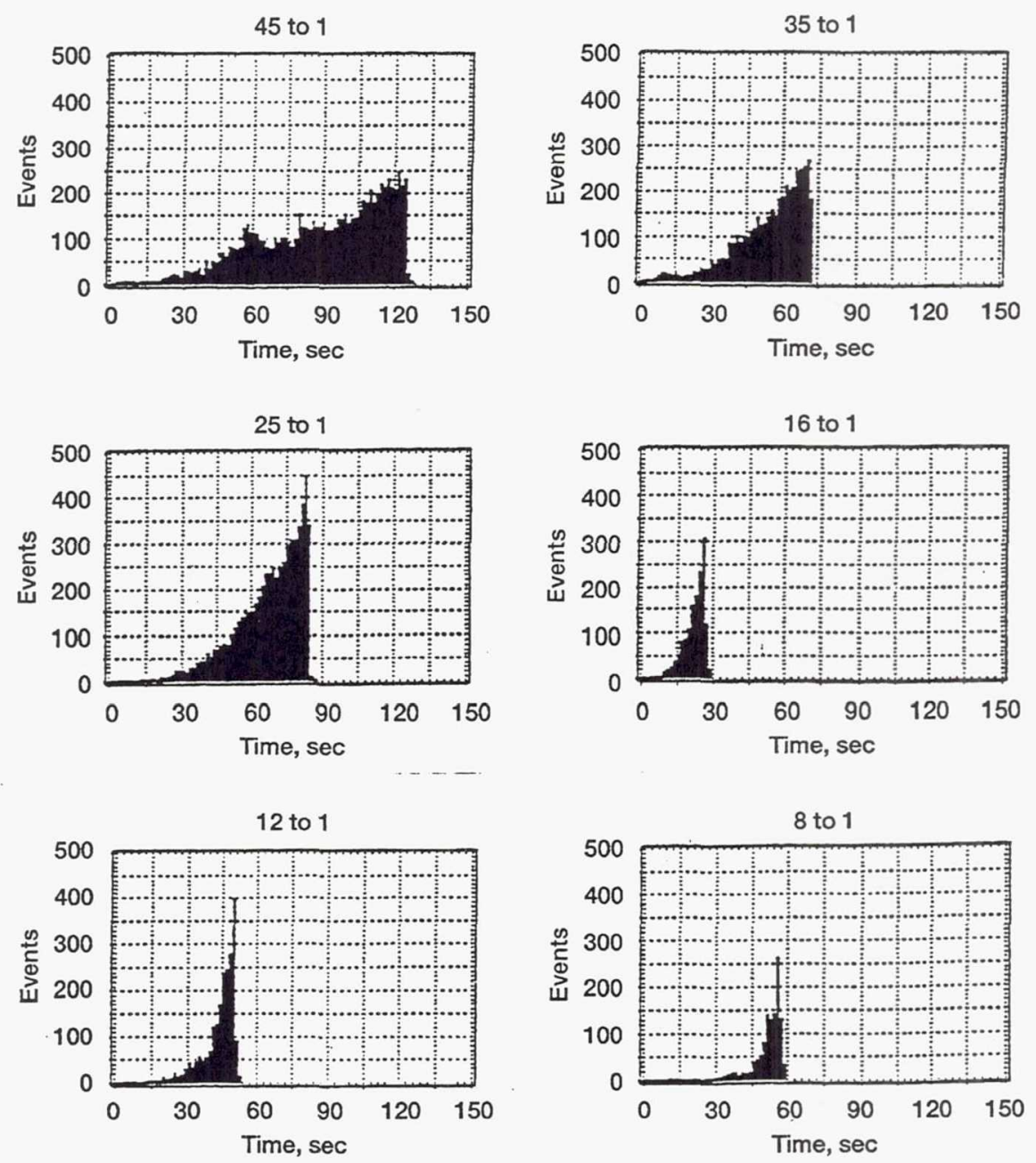

Figure 2.-Acoustic events versus time for load-deflection curves shown in Figure 1.

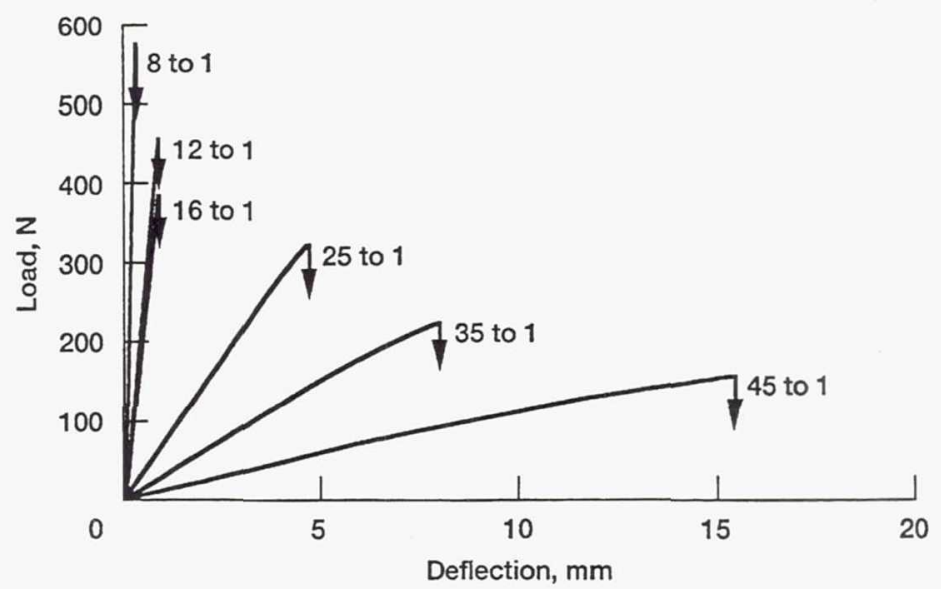

Figure 3.-Load-deflection curves for $\left(\mathrm{9O}_{2}, \mathrm{O}_{2}\right)_{2} \mathrm{~S}$ specimens tested in 3-point bending. Deflection rates (in $\mathrm{mm} / \mathrm{min}$ ) used for the various span/depth ratios are: 5 for $45 / 1,4$ for $35 / 1,2$ for $25 / 1,1$ for $16 / 1,0.5$ for $12 / 1$, and 0.25 for $8 / 1$. 

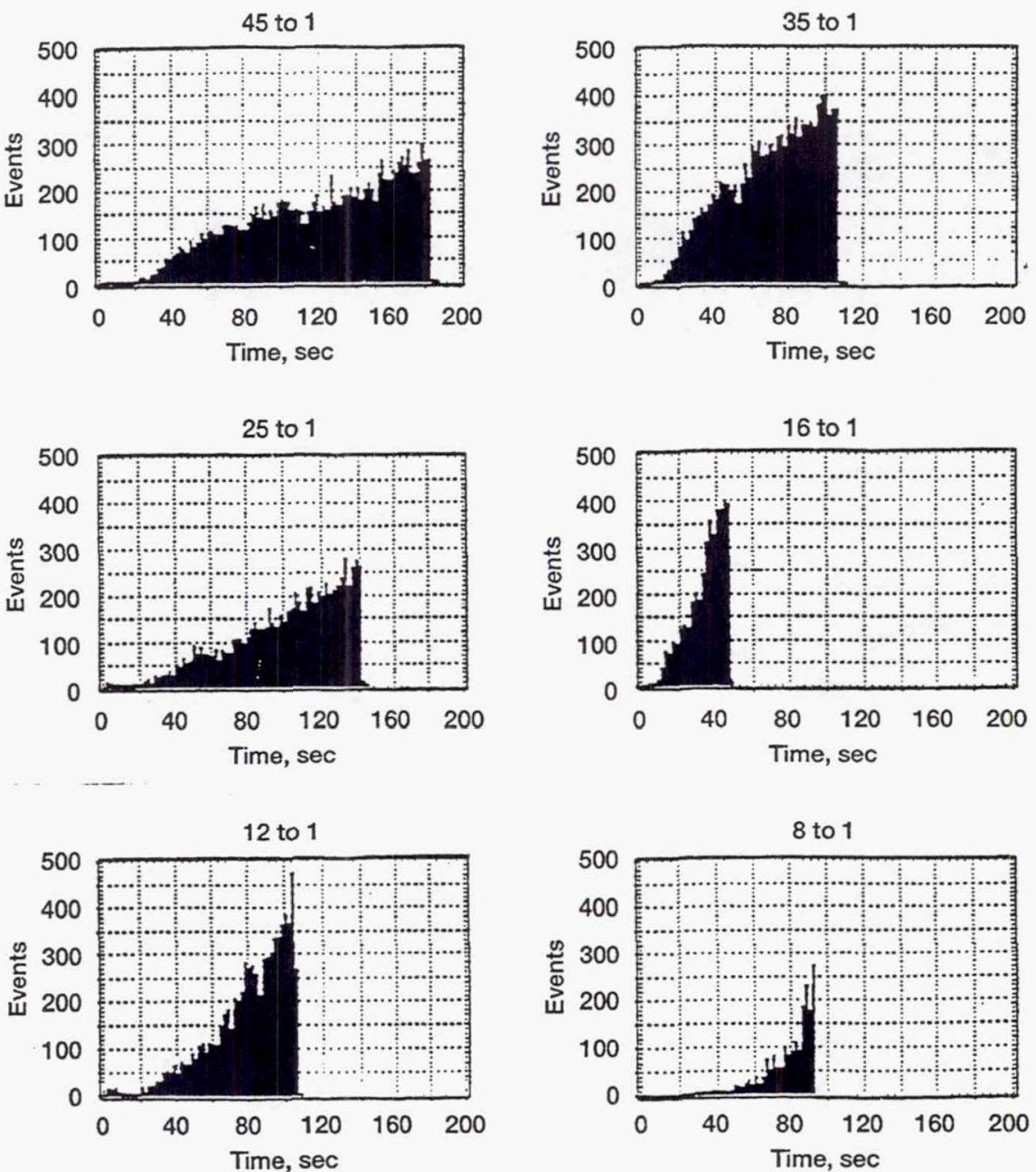

Figure 4.-Acoustic events versus time for load-deflection curves shown in Figure 3.

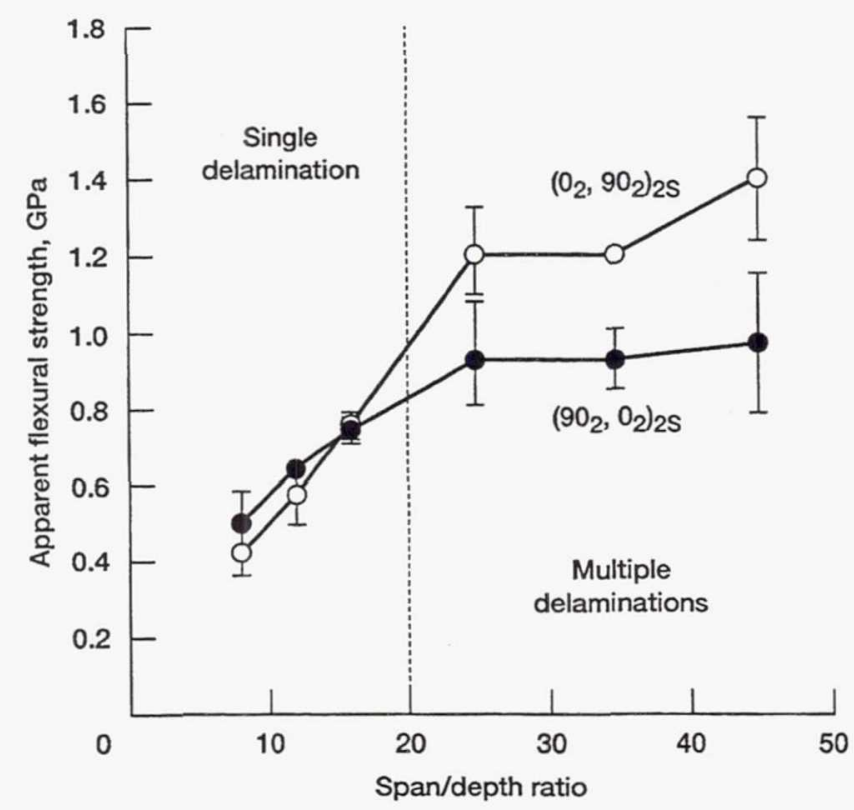

Figure 5.-Apparent flexural strength of $\left(\mathrm{O}_{2}, 9_{2}\right)_{2 \mathrm{~S}}$ and $\left(9 \mathrm{O}_{2}, \mathrm{O}_{2}\right)_{2 \mathrm{~S}}$ laminates tested in 3-point bending. 


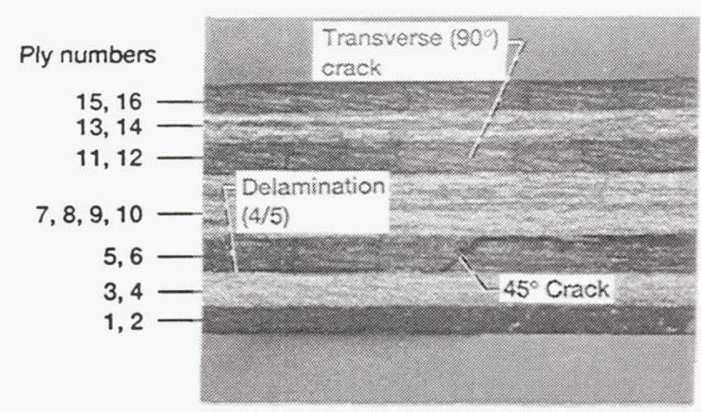

(a) $\left(90_{2}, 0_{2}\right)_{2 S}, S / D=8$.

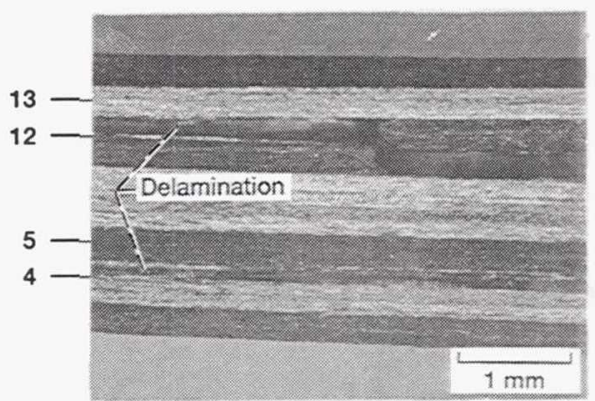

(b) $\left(90_{2}, O_{2}\right)_{2 S}, S / D=45$.

Figure 6.-Failure modes observed by post-failure analysis of 3-point bend specimens with ply layups of $\left(\mathrm{O}_{2}, 9 \mathrm{O}_{2}\right)_{2 \mathrm{~S}}$ and $\left(9 \mathrm{O}_{2}, \mathrm{O}_{2}\right)_{2 S}$ and various span-to-depth ratios.

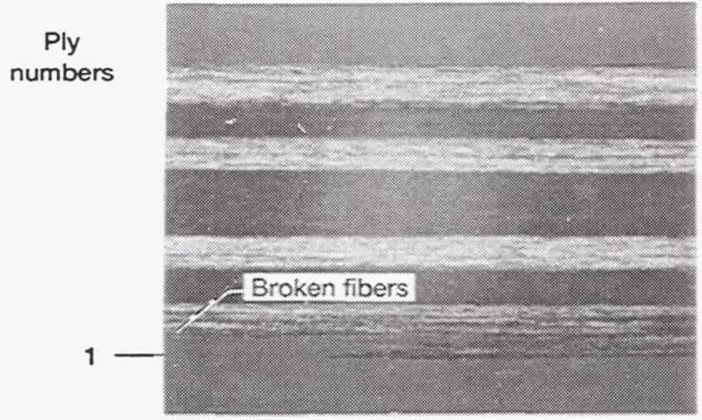

(c) $\left(0_{2}, 90_{2}\right)_{2 S}, S / D=35$.

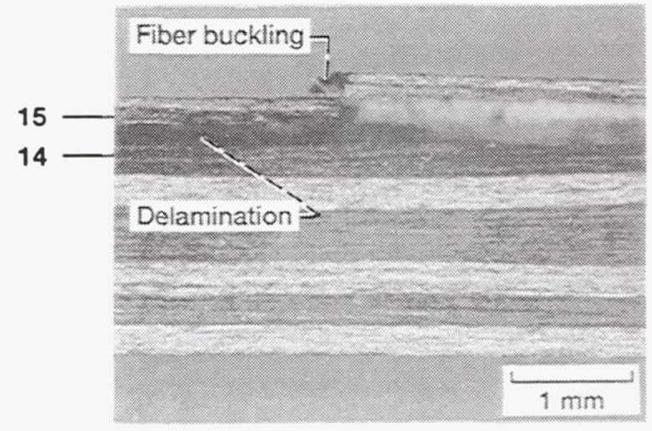

(d) $\left(0_{2}, 90_{2}\right)_{2 S}, S / D=45$.

Figure 6.-Concluded. 


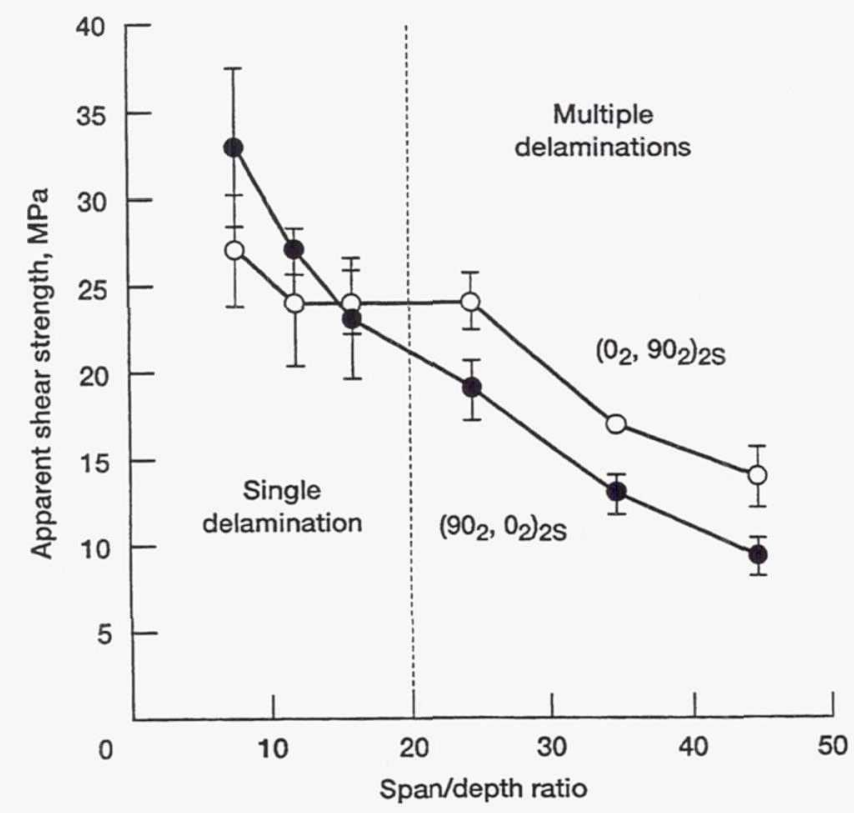

Figure 7.-Apparent interlaminar shear strength of $\left(\mathrm{O}_{2}, 9 \mathrm{O}_{2}\right)_{2 \mathrm{~S}}$ and $\left(\mathrm{O}_{2}, \mathrm{O}_{2}\right)_{2}$ laminates tested in 3-point bending.

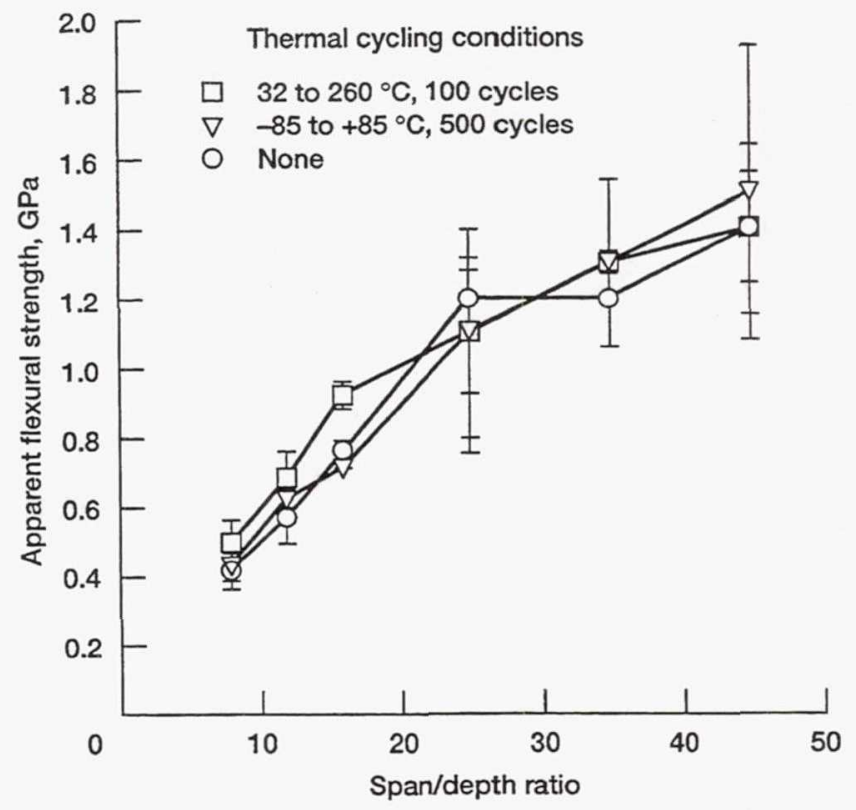

Figure 8.-Effect of thermal cycling on the apparent flexural strength of $\left(\mathrm{O}_{2}, 9 \mathrm{O}_{2}\right)_{2 \mathrm{~S}}$ specimens tested in 3-point bending.

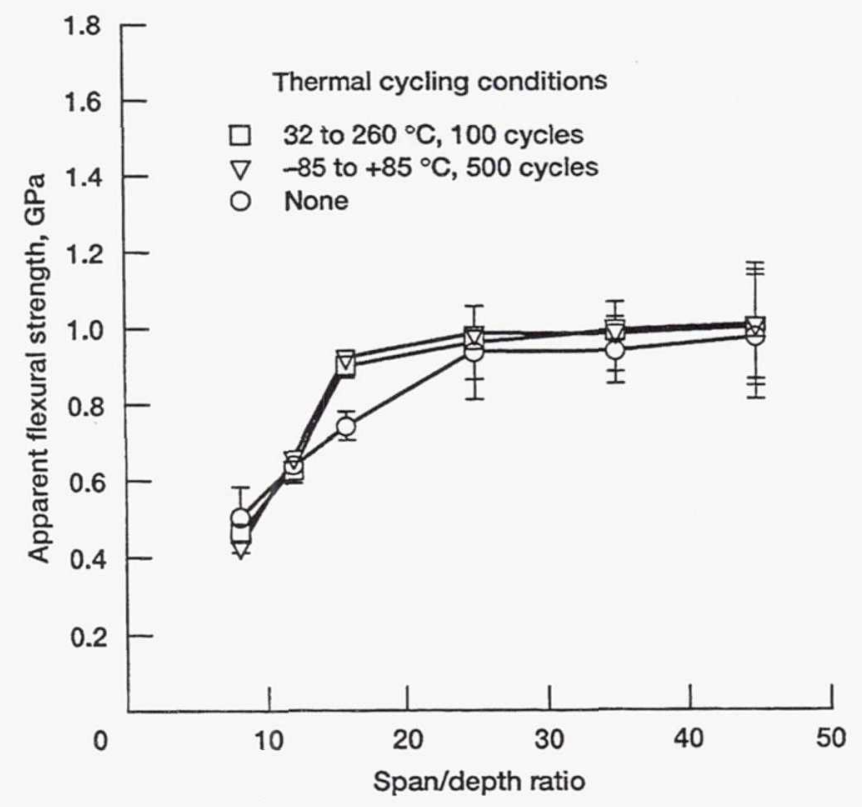

Figure 9.-Effect of thermal cycling on the apparent flexural strength of $\left(9 \mathrm{O}_{2}, \mathrm{O}_{2}\right)_{2}$ s specimens tested in 3-point bending. 

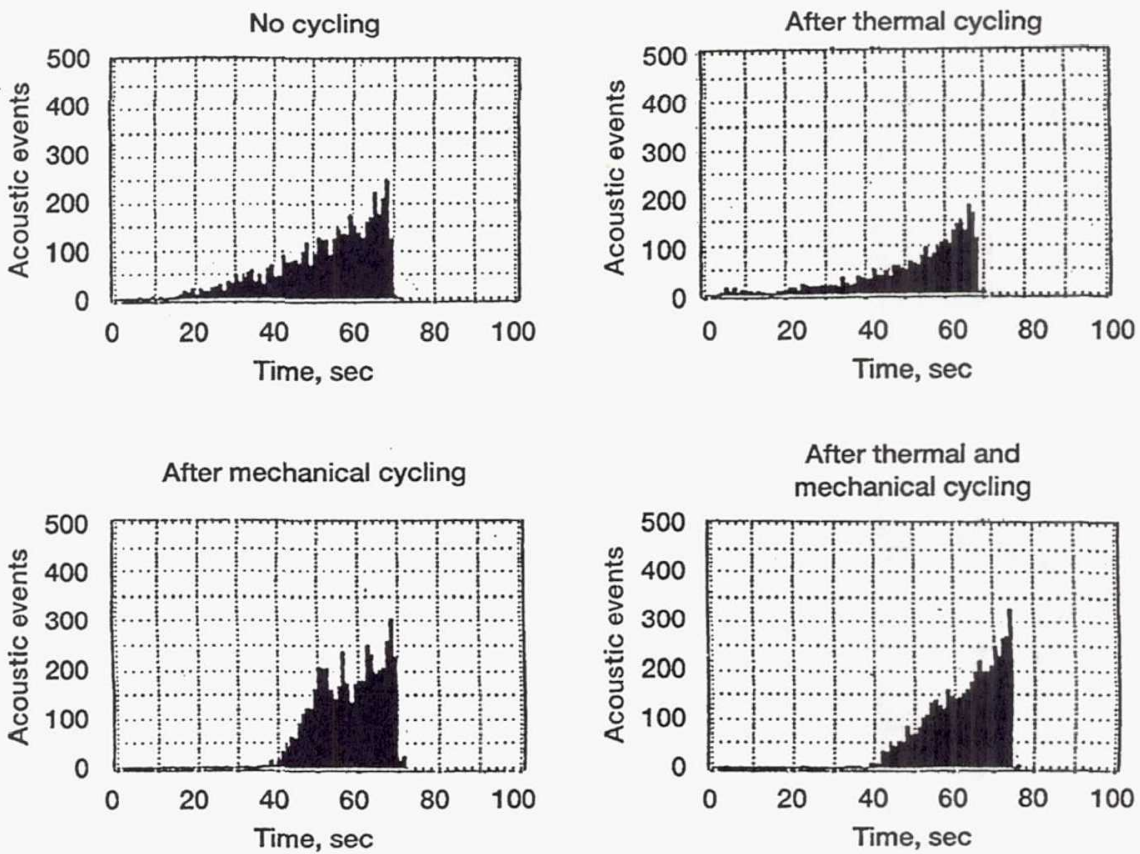

Figure 10.-Effect of low temperature thermal cycling and mechanical cycling on acoustic events recording during 4-point bend testing of $\left(\mathrm{O}_{2}, 9 \mathrm{O}_{2}\right)_{2 \mathrm{~S}}$ specimens with a $45 / 1 \mathrm{span} /$ depth ratio.
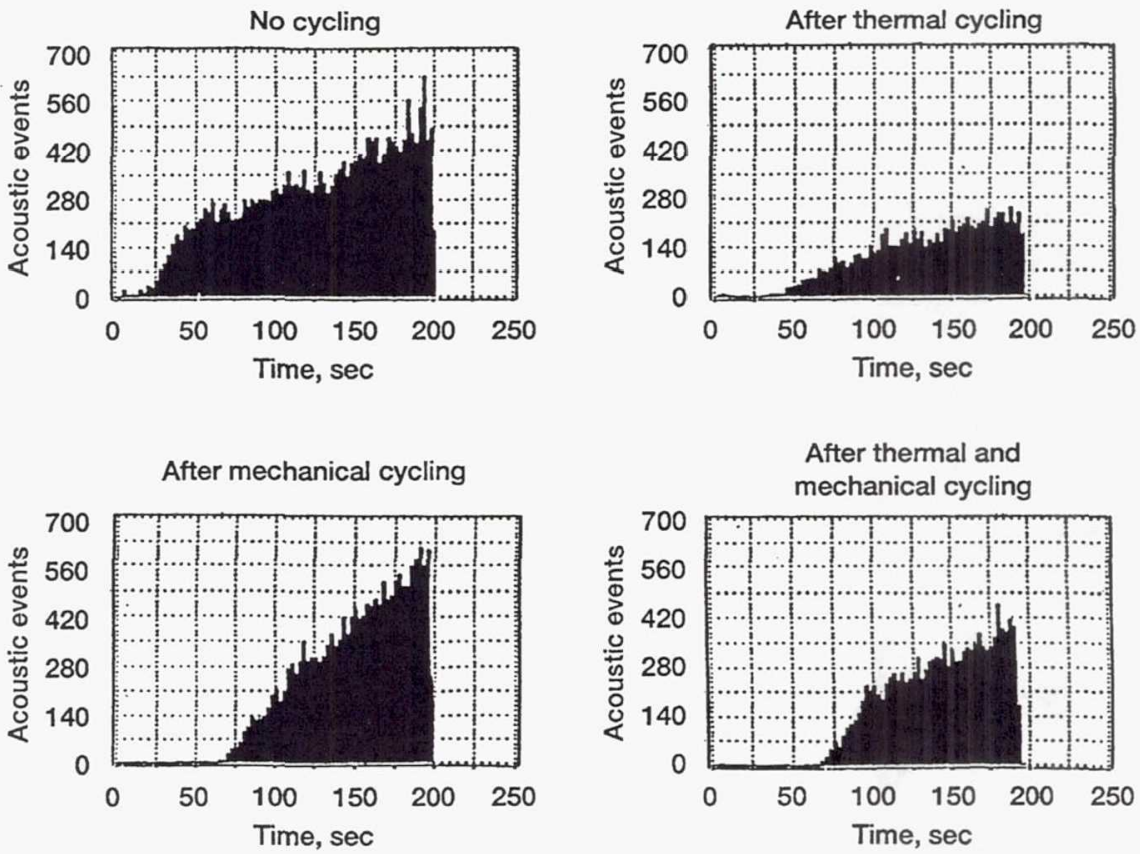

Figure 11.-Effect of low temperature thermal cycling and mechanical cycling on acoustic events recording during 4-point bend testing of $\left(9_{2}, \mathrm{O}_{2}\right)_{2 \mathrm{~S}}$ specimens with a $45 / 1 \mathrm{span} /$ depth ratio. 

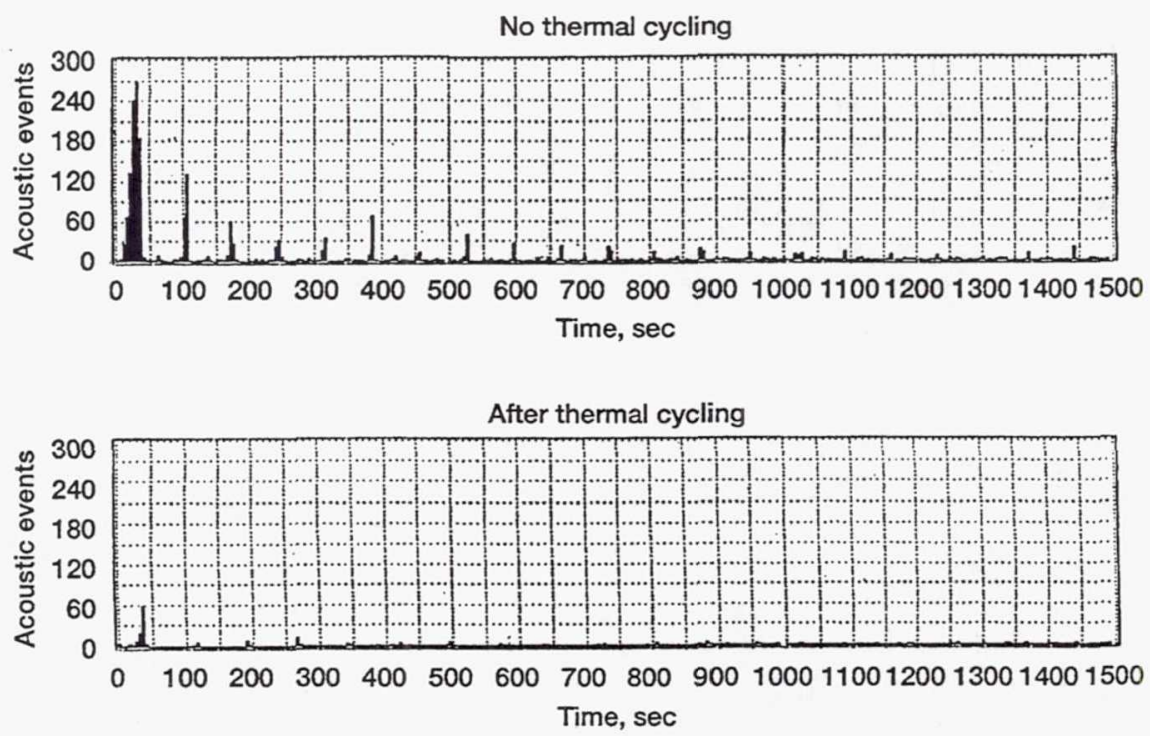

Figure 12.-Effect of low temperature thermal cycling on acoustic events recorded during subsequent mechanical cycling of $\left(\mathrm{O}_{2}, 9_{2}\right)_{2}$ s specimens tested in 4-point bend.

(Span/depth ratio $=45 / 1$. Maximum load $=50$ percent of the failure load.)
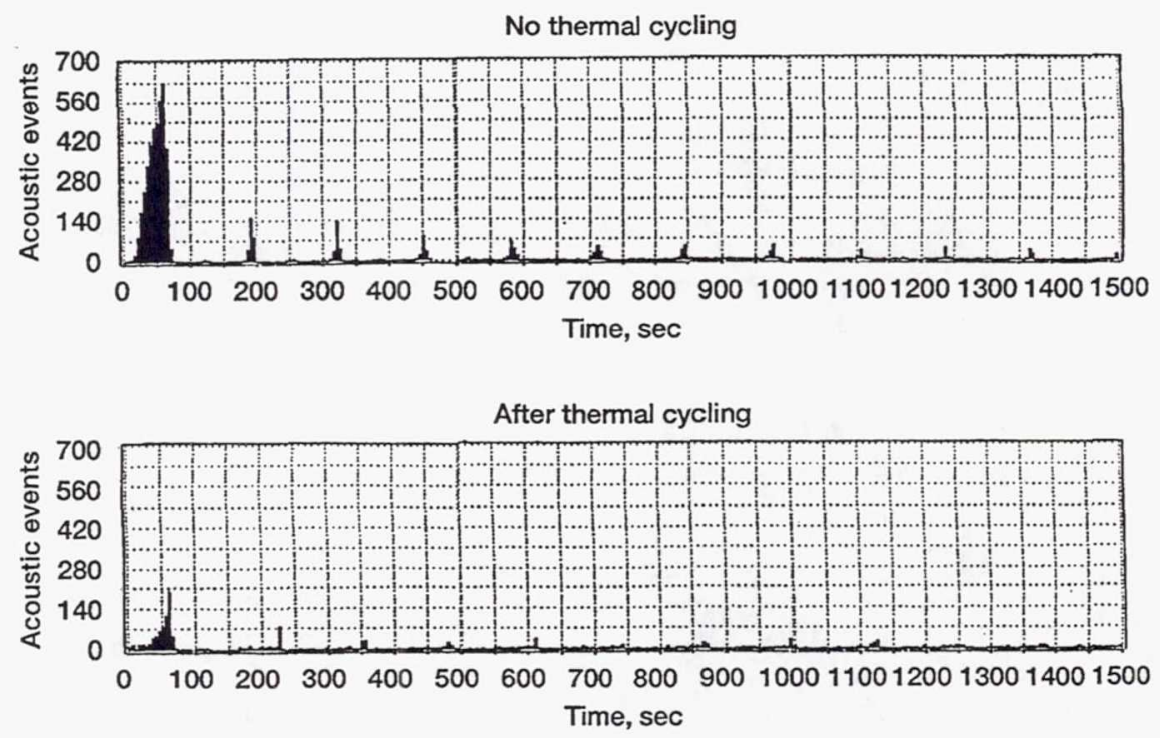

Figure 13.-Effect of low temperature thermal cycling on acoustic events recorded during subsequent mechanical cycling of $\left(9_{2}, \mathrm{O}_{2}\right)_{2 S}$ specimens tested in 4-point bend.

(Span/depth ratio $=45 / 1$. Maximum load $=50$ percent of the failure load.) 


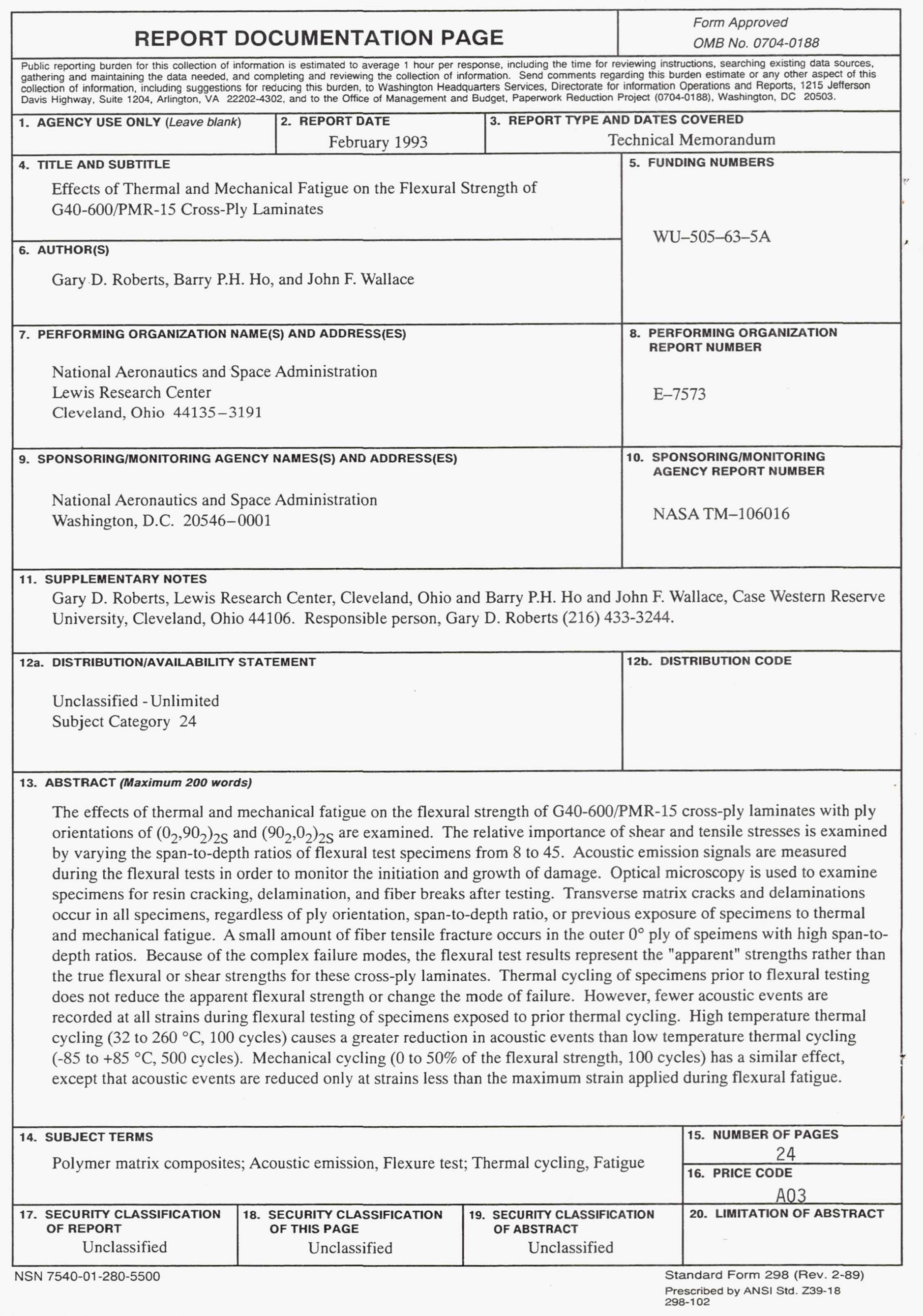


National Aeronautics and

Space Administration

Lewis Research Center

Cleveland, Ohio 44135

Otfieial Business

Penalty for Pitvate Use $\$ 300$

FOURTH CLASS MAIL

ADDRESS CORRECTION REQUESTED
|||||

Natıonal Aeronautics and

Space Administration

NASA 451 